\title{
Los Vericuetos del Cambio en Psicoterapia de Grupo
}

\section{The Twist and Turns of Change in Group Therapy.}

\author{
Isabel Sanfeliu Sataolalla \\ Sociedad Española para el Desarrollo del Grupo, la Psicoterapia y el Psicoanálisis (SEGPA), España
}

Resumen. Cuando se arma un grupo para poner en marcha el proceso de análisis, uno de nuestros objetivos es devolver a la vida de un sujeto algo que siempre se consideró inherente a ella: mudanza, transformación, alternativas entre las que dirimir, sacudidas y crisis por las que avanzar. Quien acepta nuestro encuadre se ve confrontado con lo que más necesita y teme: otros capaces de conmocionarle, desenmascararle, otros que no permitan ser alojados en moldes conocidos y le reten a contemplarse teñido de emociones rechazadas como propias.

Un caso clínico permitirá mostrar especial énfasis en la necesidad de alternancia de procesos de identificación y desidentificación en el grupo para conseguir cambios en la estructura psíquica de los sujetos.

Palabras clave: psicoterapia de grupo, cambio, identificación, transferencia, relación objetal.

\begin{abstract}
When a group is formed in order to start a process of analysis, one of our main objectives is to bring back to a subject's life a trait that has always been considered to be inherent to it: change, transformation, different choices for a solution, shaking and crisis to keep going forward. The person who accepts our setting knows that he will have to face what is most necessary and at the same time most feared: others who are able to shock, or unmask him; others that do not allow to be pushed to comfortable structures and challenge him to see himself wearing the emotions he rejects as being his own.

A clinical case will allow us to make special emphasis in the need to alternate the identification and disidentification processes in the group in order to achieve the necessary changes in the psychic structure of the subjects.
\end{abstract}

Keywords: group psychotherapy, change, identification, transference, object relation.

\section{Cambio...}

Antes de adentrarnos en el marco concreto al que alude nuestro título, tratemos de consensuar algunas ideas en torno al concepto "cambio"; cambio desde la perspectiva de un sujeto concreto condenado a su ausencia. El neurótico repite, es su condena, enredado en el conflicto, toda novedad es sinónimo de amenaza de forma que, aunque depare dolor, el desenlace que provoca está teñido siempre por los mismos matices que configuran su "síntoma". La compulsión a la repetición es un modo de expresar la inercia en el nivel psíquico. Es arduo per-

La correspondencia sobre este artículo se puede enviar a la autora a c/ Pintor Ribera 20,28016 Madrid. E-mail: isanfeliu@me.com 
sistir en esta tesitura estando inmerso en una realidad inasible en la que "todo fluye y nada permanece"... Quien sólo tiene una percepción sobre algo en todo momento y bajo cualquier circunstancia, de seguro yerra o recorta su realidad aferrado a cierto ángulo de mira, a una hora del día desde la que poder contemplar siempre el mismo paisaje. Es duro esperar, anclado en el tiempo, lo mismo -pienso en uno de mis paseos favoritos, mil veces recorrido y en el que siempre aparece una rama, un color, una piedra, un sonido o aroma que le hace nuevo-, es penoso perder la expectativa de ser sorprendido con tal de evitar lo que se presume amenazador. Cierto que como contrapunto resulta tranquilizador y fiable pisar siempre el mismo terreno.

Cuando se arma un grupo, mejor diría un agregado, para poner en marcha el proceso de análisis, uno de nuestros objetivos es devolver a la vida de un sujeto algo que siempre se consideró inherente a ella: mudanza, transformación, alternativas entre las que dirimir, sacudidas y crisis por las que avanzar. Quien acepta nuestro encuadre se ve confrontado con lo que más necesita y teme: otros capaces de conmocionarle, desenmascararle, otros que no permitan ser alojados en moldes conocidos y le reten a contemplarse teñido de emociones rechazadas como propias. Por otra parte, no conviene derribar precipitadamente las defensas, se requiere un trabajo previo que haga tolerable la angustia que el síntoma acalla. El combate de las identificaciones proyectivas se pondrá en marcha y nuestra función será desentrañarlas para ofrecer a cada cual recovecos de los que irá entresacando su propia verdad.

El cambio al que aquí aludimos concierne a la estructura psíquica, implica por tanto a las grupalidades internas de los componentes del grupo. Grupos internos organizados en torno a emociones que impregnan los vínculos significativos de un sujeto en toda su complejidad. Como bien apunta René Kaës (texto inédito para Caparrós, 2011).

"Los grupos internos son formaciones intrapsíquicas dotadas de una estructura y con funciones de ligazón entre las pulsiones, los objetos, las representaciones y las instancias del aparato psíquico. Forman un sistema de relación relativamente estable, atravesado por conflictos y produciendo síntomas. Ligan a sus elementos constituyentes por relaciones de interdependencia y forman una unidad semántica, dramática y proactiva, organizándose el conjunto según una estructura grupal”.

Convendremos en que el marco que ofrece el grupo conlleva un monto de tensión presto a poner de relieve el estilo de relación objetal y la rigidez característica del neurótico ${ }^{1}$. Facilita el desenmascaramiento de los mecanismos de defensa, introduce incertidumbre a través de elementos desligados que, al cuestionar ciertos equilibrios intrapsíquicos ofrecen oportunidad para su reorganización. La ansiedad patógena detuvo el sempiterno proceso de identificación y desidentificación por el que deambula, inconsciente, lo intrapsíquico reconstruyendo incesantemente. Lo plural de la presencia en el grupo facilitará al analista la tarea de dinamizar de nuevo el juego de agrupamientos y desagrupamientos que abrirá el abanico de estilos de vinculación.

Planteamos por tanto que una importante posibilidad de cambio a través del grupo tiene que ver con los procesos de identificación, procesos que se vienen dando en el marco de las relaciones objetales que inaugura el alumbramiento.

\section{Objetos que paralizan / objetos que transforman}

En el objeto se dan cita interno y externo, lo intrapsíquico teñido de emociones adheridas a imagos inconscientes y lo social sintetizado y anclado en un individuo. Los objetos del entorno ponen en marcha y modulan el proceso vital del recién nacido, son objetos que pierden algo de su identidad al ser atrapados en representaciones en el interior del sujeto en ciernes. Así, narcisismo y objetalidad, investimiento de Sí mismo y del afue-

\footnotetext{
${ }^{1}$ Ya expresé en otra ocasión (Sanfeliu, 2007) cómo considero que evoluciona el espacio a lo largo del proceso de un grupo de psicóticos. Carencia o conflicto remiten a dos formas de enfermar: Déficit como lugar de no experiencia, donde nunca se inscribió significado, vacío provocado por una angustia desbocada, ni contenida ni elaborada, que impide que la experiencia se dé: una acción carece de sentido, de significado, no deja huella que pudiera conducir a la simbolización. En el Conflicto (neurosis) se enfrentan contradicciones, los opuestos. La respuesta que ofrece el grupo terapéutico en cada caso es distinta.
} 
ra (encarnado también en el objeto interno), mantendrán una tensión a lo largo de nuestra existencia que, en un sujeto sano, deambulará entre uno y otro polo en función de las circunstancias. El proceso de subjetividad es un discurrir cambiante e interminable entre ambos extremos, de aquí podría desprenderse que amor y odio -sus emociones concomitantes- son dos utopías inalcanzables y a la vez fértiles, cuya dinámica resultante se resume en el deseo.

La condición inicial del objeto es externa, pero su internalización se antoja decisiva para que adquiera esas valencias psicológicas que lo erigen en constituyente de la entraña del sujeto. Las fijaciones significativas primeras, pasan a ser organizadores a los que el sujeto regresa ante la pérdida. El objeto externo, ese que desaparece, no es nada en sí, el significado se ha trasladado a la interioridad y es la sombra del objeto interno la que oculta y anega al externo, la que encubre las claves del deseo que se abre paso a través de representaciones incorporadas en sujetos del grupo. Cada sujeto es, justamente, lo que no puede alcanzar: la suma estructurada de los objetos externos que introyecta, proyecta, con los que se construye en un inútil y sin embargo, fructífero anhelo. Todo ese drama sucede de forma peculiar en cada vida concreta, en épocas diferentes, con intensidad y ritmos distintos e irrepetibles a través sucesivas identificaciones.

En este recorrido se sucedieron estimulantes vínculos que alentaron crecimiento y otros que se hicieron cómplices de resistencias contra el proceso vital de cambio, que atraparon en la mortecina compulsión a la repetición. Topar con las nuevas rivalidades que ofrece el encuadre grupal incita la multiplicación de identificaciones proyectivas a través de las que pesquisar los viejos conflictos.

El concepto de identificación puede apuntar a la construcción de un sujeto, a la búsqueda o encuentro casual de referentes para "ser", para "ser con", ser "frente a", ser "como...", ser "otro", para averiguar quién es quién y descubrir la diferencia y con ella la identidad. En el primer caso -que queda arraigado como modelo para la trashumancia por una vida tejida con identificaciones-, el nacimiento de un nuevo integrante en el grupo familiar genera un momento traumático en las relaciones objetales de su entorno; las transacciones narcisismo/objetalidad se alteran y provocan redistribución de investimientos ${ }^{2}$. También la llegada de un hermano reorganiza el quién es quién en la familia; es un revulsivo que dispara pesadillas en lo imaginario, reactivadas quizá ulteriormente por la simetría que depara el grupo terapéutico.

Entre los muchos procesos que tienen lugar en la estructuración del psiquismo, la identificación es una de las claves más importantes. Identificarse con alguien es establecer una relación de mismidad con la representación de esa persona y el proceso identificativo acompañará nuestra existencia modificando gradualmente estructura y organización interna. Tras cualquier identificación subyace la identificación primaria que aconteció en el sistema madre-bebé; ambos se renuevan en una relación indiscriminada en la que la capacidad simbólica del adulto irá dotando de espacialidad al nuevo ser, creándose un vacío donde este irá ubicando lo propio, lo que es ajeno y, más adelante, al objeto. La identificación primaria es una primera discriminación de tipo muy precario sobre la que se asentarán posteriores diferencias.

Como ya apuntamos en otro lugar (Sanfeliu, 1998), gradualmente entra en escena la identificación secundaria en la que intervienen procesos de simetría (lo que iguala sujeto y otro) y asimetría (lo que los distingue). Adquirida la capacidad reflexiva, se accede al simbolismo para ingresar en el universo de reglas; el niño adquiere conciencia de que pertenece a ese mundo por identificar, es sujeto y objeto, ente de reflexión y reflexivo, la palabra ha posibilitado la distancia para pensar sobre sí. En el horizonte, nuevas representaciones que se vinculan, inéditas fuentes de angustia y la temporalidad que instaura lo histórico, a partir del forcejeo interminable entre principio de placer y principio de realidad.

También puede abordarse el concepto identificación en relación con la empatía, observando su efecto en el territorio compartido. Las transacciones entre grupos internos y la multiplicidad de representaciones que coexisten en el espacio intrapsíquico del grupo, facilitan la plasticidad para ponerse en el lugar del otro, el grupo gana cohesión y -quizá paradójicamente- los individuos adquieren independencia. Internalizaciones y exterio-

\footnotetext{
${ }^{2}$ El inerme bebé es incapaz de lidiar por sí solo con sus violentas y vitales pulsiones; el objeto que sacie necesidades, permitirá que se le identifique como algo externo que a su vez identifica al recién llegado.
} 
rizaciones se suceden en un nuevo contexto que acoge y modifica los muchos objetos internos que bullen en él; el proceso identificativo imprime dinámica a la reestructuración: identificación (reconocimiento de lo viejo en lo nuevo) $\Rightarrow$ desidentificación (posibilidad de ruptura) $\Rightarrow$ identificación (acceso a nuevos modos de vinculación). Crear lo propio a partir de lo diverso que ofrece el grupo como sistema de representaciones: el otro real, mi representación del otro o el otro en mí, yo en el otro, lo que el otro me deposita, el otro mirándose en mí, los otros sin mí, y al menos tantas representaciones de mí como integrantes tiene el grupo.

La distancia sujeto/objeto es eliminada fugazmente por la identificación, la estructura del conjunto (continente grupal) favorece la posibilidad de generar y absorber contenidos; los límites regulan intercambios entre diversos niveles en entrecruces de verticalidades en el aquí y ahora. Así, en un ir y venir del narcisismo a la objetalidad, del Sí mismo a un Real que se deja disfrazar menos de lo habitual por las interpretaciones a que es sometido, el proceso identificativo, detenido en las patologías neuróticas, puede continuar su trayectoria. Es el trabajoso camino para devenir sujeto.

Los procesos objetales pueden contemplarse aquí desde una perspectiva estructural: lo económico al activarse lo pulsional; lo tópico impuesto por el objeto real cuya sombra acoge los imaginarios y lo dinámico como interjuego de fuerzas que se abre paso a través de la ambigüedad conflictiva... No cabe duda, lo grupal ocupa un lugar específico en el marco de las teorías objetales.

\section{El grupo}

En toda época y lugar los sujetos tienden a vivir en común y la convivencia engendra colaboración, competencia y lucha. En esa intersubjetividad despunta la identificación con el otro indispensable para llegar a la discriminación de uno mismo, identificación en la que también se acodará una estructura psíquica. La distinción individuo-sociedad es ficticia, desde que el sujeto nace se encuentra en una situación concreta que es tan sólo un fragmento de la realidad que percibida o no actúa sobre él, de la que se interiorizan segmentos impregnados de emociones. La realidad viene dada, pero cada cual le asigna distintos significados y, de otra parte, con su intervención la modifica. La subjetividad del sujeto, la percepción de sí mismo está en relación directa con su medio social, es el representante civilizado de la supervivencia de fases arcaicas de la cultura.

El paradigma grupal integra Yo y Objeto, Self y objetos del Self, lo más íntimo en la máxima exterioridad que envuelve como marco institucional al conjunto. Interpersonal, transpersonal, interpersonal, facetas todas insumidas por la trama del grupo. Aún en el silencio, el otro impregna en distintos niveles de profundidad la propia imagen que se reconoce y cobra autonomía dentro de la identidad grupal, en un reflejo complementario de aquella mirada primigenia que creó conciencia de ser.

Un reto: encontrar el propio espacio en el grupo, ser con otros, herida narcisista ante la fratria que, al mismo tiempo, aporta una identidad diferenciada. Los objetos internos de cada integrante modulan la estructura y el proceso: la mirada de un sujeto recorre, entre precavida y curiosa, a los otros moradores de ese peculiar espacio que, aún escogido libremente, se teme; los otros son a su vez espejos que devuelven perfiles esperados, inéditos en ocasiones, provocadores en cualquier caso. Verse como se es visto para alcanzar a contemplarse, identificar al otro con otros que le precedieron... ¿Qué vicisitudes atravesarán los procesos inconscientes en la configuración grupal?

El grupo se configura como estructura pero las fronteras que lo delimitan no vienen dadas por el entorno físico, se irá estableciendo un espacio contenedor a medida que las intervenciones del analista acompañen el proceso. El grupo es el medio por el que llegar a lo recóndito reprimido, no es algo tangible; como evoca Napolitani (1998): el individuo es un objeto de nuestra percepción que se caracteriza por su finitud en el espacio y constancia en el tiempo, a diferencia del grupo que carece de constancia y límites objetivamente definibles.

Las identificaciones proyectivas de unos luchan por imponerse a las del otros; en el fragor de la batalla se espera que el analista logre ponerlas de relieve, metabolizarlas mientras se abren paso primitivas ansiedades y 
se evacúan aspectos pulsionales no integrados hasta el momento. Representaciones de objetos internos colman un espacio donde imaginario y real confluyen transformándose, anclados en la experiencia con el grupo que rodea.

El sentimiento de pertenencia amansa la angustia compartida y se desencadenan diferentes procesos simultáneos en cada sujeto. Entreverado con la identificación surge lo siniestro (Unheimlich), esa inquietante extrañeza cargada de ambigüedad en la que coexisten elementos fantásticos con una percepción de la realidad, vivencia de simultaneidad de lo interno y lo externo a través del objeto familiar hace mucho olvidado y reprimido. Plasmar esa inquietud en palabras alejará fantasmas y los afectos podrán encarnar representaciones ancladas en la biografía de cada cual. El proceso avanza entre inmersiones verticales (identidad como sujeto) y puestas en común desde lo horizontal en el aquí y ahora (identidad grupal, pertenencia).

\section{Daniel}

Ofrecemos una pequeña sinopsis de cómo transcurrió un proceso grupal durante nueve meses, tomando como referente a un paciente concreto al que llamaremos Daniel.

Daniel es el menor de cinco hermanos. Su madre es "un pedazo de pan", que tiende a la sobreprotección y sufrió una crisis depresiva una vez criados todos los hijos. El padre, serio, duro, "es un tiburón en los negocios" respetado por todos y al que Daniel sacó siempre cualquier capricho. El hermano mayor, "oveja negra" en la medida que no sigue los dictados del progenitor, deja de estudiar con dieciocho años, triunfa, despilfarra y es feliz a pesar de haber sido una víctima más de la crisis económica en nuestro país (a Daniel le molesta y da pudor que el padre no reconozca méritos a este hermano, mientras contempla con orgullo la brillantez con la que él sacó adelante sus estudios). Sigue una hermana depresiva que le genera una importante carga de ambivalencia, luego un hermano que se independizó del cerrado núcleo familiar y, por último, tras Daniel, la pequeña, "un torbellino que puede con todo". Daniel llegó a consulta sufriendo "un orden obsesivo sin el que me descabalo" y temores hipocondríacos; gran matemático y racionalizador, sufre una crisis al acercarse un tiempo al negocio familiar en el que se enfrentó al dilema de "humillar" a la familia (tomando él la dirección) o humillarse él manteniéndose en un segundo plano aparentemente incompetente y deprimido. Otros pacientes le descubrirán "extrañas" conexiones entre sus síntomas y las circunstancias en que se desenvuelve.

En el grupo tendrá que vérselas con Diana (canaria de núcleo depresivo, la superstición acoge lo violento de sus pulsiones, "soy asî” y se aferra a esa convicción; tiene dos hermanos problemáticos, de ella se espera todo), Bea (coqueta, lagartija... su abuela la amenaza con suicidarse tras tratar de agredirla con un cuchillo; ella alardea de sus deseos de venganza pero quedan bloqueados y la rabia solo asoma a trompicones), Andrés (esquizoide, inquietante para mi compañera de equipo, está "hurgando" en la relación con el padre, se sorprenderá celoso con una chica) y Pilar (mujer potente que batalla con su talante depresivo, encarna "el sentido común" y tiende a autoexcluirse; padre inquietante: admirado y vilipendiado, maltratador y afectivo).

Veámosles en acción a través de algunos fragmentos de una sesión tomada al azar:

Acaban de robar el bolso a Diana y está muy preocupada por las llaves de su piso compartido.

- Daniel (tranquilizándola): "No son profesionales, sólo quieren el dinero, la cámara y el móvil".

- Diana dice que se está "emparanoiando", se le pregunta por qué cree que su miedo es excesivo. "Es por las compañeras de piso, me siento responsable...".

- Pilar recuerda que a ella también se lo robaron y lo encontró en una papelera del metro...

- Bea: "A mí me pasó dos veces".

- Daniel: "Yo también hago un mundo de un grano de arena..." y comenta el temor a que se desprenda una chapa de su nave, dé a un coche, provoque un accidente... "empiezas y no hay manera de parar... Siempre he sido así, me gusta llevarlo todo tan controlado que cuando algo se me escapa no puedo ni dormir". 
Hasta aquí "el grupo" envuelve a la compañera que sufrió un ataque del exterior. Se suceden reacciones en cadena desde la identificación, solidaridad desde lo simétrico; se sienten menos incómodos compartiendo el síntoma y la atmósfera es contenedora. Aprovechamos para indagar lo dispar, lo peculiar de cada cual explorando desidentificaciones.

- Terapeuta: "Daniel se da esa explicación; ¿los demás...?”.

- Diana: "Yo creo que soy una paranoica, si alguien duerme con una estantería encima creo que se le puede caer, o si estoy fumando que puedo quemar, realmente no se puede vivir asî”.

- Andrés: "Yo estaba así hace un año".

- Daniel: "Todo va al mismo sitio, peligro, le abre la cabeza y le mata".

- Pilar: "Yo también me como la cabeza pero no por esas situaciones, a mí me preocupa lo que piensen los demás de mí, lo que dicen...”.

Se esboza algún matiz que les discrimina, pero tras tantos miedos late rabia contenida; la terapeuta incorpora un emergente que intuye tiene relación: recuerda que, en la sesión anterior, todos se mostraron muy protectores de sus hermanos...

- Diana: "Prefiero que me pase algo a mí antes que a los demás".

- Pilar: "Tenemos en común la baja autoestima, por eso nos defendemos tan mal. Para mí defenderme es agredir y la agresión me bloquea".

- Daniel: "Somos muy permeables, nos dejamos influir por todo lo que nos rodea".

- Pilar: "Depende, a mí no me afecta todo el mundo".

- Daniel: "Nos bombardean con malas noticias y lo que nos pasa nos recuerda cosas que vimos que ocurrieron".

Se escabullen y la terapeuta señala a Diana el contraste entre la indefensión que siente y la violencia con la que llega a defender a sus hermanos. Se abre un interrogante a Bea, silenciosa hasta el momento.

- Bea: "No sé, estoy muy malita, estoy indignada con lo que en estos días se dice sobre el Hospital [en el que trabaja]". Muestra su irritación defendiendo a los compañeros (generan menos ambivalencia que los hermanos). Adopta la misma posición que en su familia: los padres [dirección del Hospital] toman las grandes decisiones, pero en el día a día ella es cabeza de familia, se encarga de su hermano pequeño y de la organización de las casa. De nuevo el contraste entre la indefensión y la fuerza para sacar adelante problemas de otros.

- Bea: "En casa me enfurezco pero sigo haciendo lo mismo porque les quiero, pero el Hospital, aunque me guste, es distinto".

La terapeuta retoma el comentario de Pilar: "defendernos es agredir al otro" y cómo lo resuelven de distintas maneras, Bea se enfada muchísimo, otros se obsesionan tratando de controlar todo...

- Bea sugiere a Daniel ser más desordenado, "me pondría muy nervioso", responde. Bea insiste: "Se puede, yo lo conseguí. Era horrible, tenía que colocar las mesas justo en la rayita y no podía dormir si no estaba todo en su sitio...".

- Daniel: "Tengo una serie de rutinas, pero me va bien, por eso no quiero romperlas. Sólo si estoy cabreado, rebelde contra mí, pienso que le den y me acuesto porque estoy cansado. El problema es que tendría que ser desordenado en el orden de mi cabeza, eso es lo complicado, pero eso es obligarte a hacer algo que... quiero llegar no al desorden, sino a que no me angustie la necesidad de controlarlo todo, que sea más liviano pero sin obligarme".

- Bea: "Cuando veía que habían tocado algo de mi habitación hacía de tripas corazón porque si no, no paraba hasta colocar la habitación entera. Pero ya llevo un tiempo en que estoy muy a gusto en casa".

- Pilar: "A mí también me pasa ahora". 
Mostrar rencor es para ellos ardua tarea que conviene poner en marcha. La terapeuta señala que estar a gusto en casa es estar a gusto consigo mismo. Perderse el miedo, perder el miedo a ser el monstruo del que hablan a veces, eso es lo que permite dejar de ordenar armarios.

- Diana: "Si no lo coloco todo creo que me voy a levantar sonámbula por la noche".

- Daniel: "Siempre fui ordenado pero nunca lo consideré un problema".

- Terapeuta: "Parece que compartís el deseo de que nada se mueva, que todo quede como está, bajo control".

- Diana: ¿Sabéis que pensé que me habían robado el bolso por quedarme con un dinero del banco?, como si fuera un castigo de Dios".

- Terapeuta: “¿QQué habría hecho Pilar cuando la robaron el bolso?!".

- Pilar: "A mí todo me pasa por ser demasiado buena; iba en el metro, me empujaban, uno me preguntó, le respondí y otro me robó".

- Daniel: "De verdad, querría ser malo, que todo me diera igual. No sentirme tan responsable".

Al menos se puede expresar ese deseo. Ofreciendo alternativas al dilema sometido/cruel, la terapeuta recuerda a Daniel lo logrado en su familia expresando su disentir y haciéndose escuchar en una discusión.

- Bea: "Yo no soportaba que mi madre y mi hermano discutieran, me ponía en medio. Tuve que darme cuenta de que yo no era la madre, no era mi responsabilidad".

- Terapeuta: "Antes, colocar la mesa era colocar a tu madre y a tu hermano. Al darles autonomía te la das a ti y estás más relajada".

- Bea: “Ayer mi madre me dejó perpleja, vino a darme un achuchón y me abrazó diciendo ¡mi niña!”.

- Terapeuta: "La ternura no puede salir cuando se tiene bloqueada la rabia".

- Diana: "Yo sólo soy cariñosa con los animales, a mis padres nunca les dije te quiero. Si me abraza un amiga le digo ¡quita!".

- Bea: "Yo también, me da vergüenza".

- Diana: "En mi familia nos cuidan, es su forma de querer. Mis problemas empezaron porque mi padre era muy machista, no me dejaba salir ni a la vuelta de la esquina".

¿Cómo identificar el cariño torpemente expresado por sus familias? Hace poco dedicamos un trabajo (Sanfeliu et al., 2009) a la ternura como contrapunto de la violencia en el contexto de la psicoterapia de grupo. Libertad = abandono (¿lo sentía así el padre de Diana?), la libertad entraña riesgos...

- Pilar: "Recuerdo lo mal que lo pasaba con mi jefe, se ponía protector como mi padre. Pero el otro día mostré mi enfado con calma, me quedé muy a gusto, ya no necesito alterarme para decir las cosas. Era un círculo vicioso, desde el miedo a descontrolar me callaba, pero acababa por estallar y luego me sentía fatal".

Se ven frágiles habitualmente, pero existen ámbitos en los que algunos despliegan la fuerza y el valor que se retacean fuera de ese margen; así Daniel como corredor de rallys, Pilar en viajes solitarios a lugares inhóspitos. Reconocen su fuerza, pero...

- Daniel: "Somos de arcilla, nos moldeamos para que no piensen que somos unos bestias".

- Andrés comenta a Pilar que está atrapada por lo que piensen de ella en su trabajo, por el miedo a dar otra imagen y, sin embargo, en el grupo es muy valorada siendo como es.

- Diana: “A mí me gustan los chicos más pequeños, te miran con admiración”. Y relata sueños de violación que muestran contradicciones que bullen en su interior: dominar/ser dominada, idilio/pasión.

- Bea: "Qué mal lo pasé de niña al ver a mis padres enrollados". 
Las pulsiones se abren paso y lo sexual ocupa su lugar, aunque todavía tímidamente y de la mano de los extremos (amores platónicos y violaciones) a que en otras áreas nos tienen acostumbrados. Cómo se contemplan obtura a veces la posible seducción:

- Bea se asusta porque una amiga le tira los tejos.

- Pilar: "Tengo complejo de marimacho, de cara de bestia". Se recuerda a su padre, pero aunque extremadamente violento en ocasiones, con ella fue cariñoso y de niña sí tuvo sensación de familia. Lo que dice no entender es lo paradójico de la familia de Bea, donde ella hace de madre del hermano, de cabeza de familia...

- Diana: "Creo que mi padre se avergüenza de mi hermano. Querían un chico y nací yo y con cara de sindrome de Down (ahora es guapa)".

- Daniel, sorprendido, se apunta a todas y Andrés comenta que su hermana mayor no ejerció de tal: "Reclamar espacio no es lo mismo que ser egoísta... a veces racionalizo demasiado".

- Terapeuta: "Hay que estar malito, ser el pequeño para tener las cosas que uno quiere o... ¡saber protestar!".

$Y$ surge un coro generalizado que reivindica la posibilidad de "ser malos". Se habla de evadir responsabilidades, de cómo eso modificará la imagen que los demás tienen de uno, ¿se les querrá igual?...

- Diana: “¿Cómo lograrlo sin decepcionar a mi padre? Dejo de estar a la altura pero me voy queriendo más".

- Daniel: "Mi padre era muy responsable, toda la familia delegó en él, yo le vi tan importante...".

- Pilar: “¿Por qué delegaron en mí mantener a la familia unida? Soy la mayor...”.

- Daniel: "Mi padre era el pequeño, yo también lo soy...".

Ahora se puede hablar de la envidia a los hermanos con más desinhibición, de los sentimientos enfrentados entre omnipotencia y complejo de inferioridad, del miedo a no ser imprescindible y dejar de ser querido...

- Daniel: "No nos defendemos porque mamá está detrás". Protegidos a costa del sometimiento.

A la siguiente sesión Daniel llega muy hipocondríaco; él mismo lo une a que tiene a la suegra en casa y su abuelo está muriéndose. Se debate entre el miedo a emocionarse y el temor a no hacerlo. "Les he perdido como referentes, ya tengo mi propia familia. Ahora sé por dónde van los tiros, asumí un rol que no quiero. Me molesta mi imagen exitosa, me siento en la obligación de hacer algo por ellos, pero me empaché de familia...". En su esfuerzo por animar a la independencia a otros integrantes del grupo, Daniel se dio permiso para también él transgredir ese duro código moral con el que trataba de ser fiel a los dictados de su padre (triunfar en el terreno laboral) y de su madre (cuidar de sus hermanos).

\section{Reestructuración}

Hicimos alusión al cambio, cambio que en lo que concierne al psiquismo hace referencia a la reestructuración del mismo. Las idas y venidas, las interrupciones ${ }^{3}$ de todos los integrantes (con un peso específico del analista), los encontronazos entre la imagen con la que uno se identifica y con la que se le identifica desde otras perspectivas, tantas como sujetos conforman el grupo, sujetos que a su vez incorporan racimos vinculares que también se actualizan simbólicamente en el grupo actual.

Este conjunto de relaciones objetales tiene lugar en un marco social que asimismo ostenta normas, criterios de referencia en torno a los cuales el sujeto determina su identidad. Lo social se tiñó a su vez de subjetividad

\footnotetext{
${ }^{3}$ En el sentido de intrusiones imprevistas que cortan el reiterado hilo asociativo de resistencias neuróticas.
} 
con los objetos concretos que poblaron el universo de representaciones internalizadas. En el camino -y por siempre- a través de la cotidiana confrontación en lo Real de narcisismo y objetalidad, se incorporan cambios de actitud, de percepción, búsqueda de nuevos puntos de anclaje como referentes... ¡cuántas formas potenciales de interpretar o percibir un estímulo! Nuestros pequeños grupos terapéuticos inquietan -siempre que se evite caer en un acomodo familiar iatrogénico-, reactivan síntomas, trastornos que se plasman en el modo de comunicarse y en matices que caracterizan los vínculos que se establecen. Al ponerse en juego la estructura triádica y reeditarse dilemas edípicos y fraternos, la imagen corporal también se desazona; la organización del Sí mismo se sume en una dinámica de pérdidas y ganancias, de movimientos regresivos y reestructuraciones. De esta forma quedan en entredicho rígidos modelos de identificación, adquiriéndose otros nuevos que conforman el proceso de cambio que venimos defendiendo donde la estructura psíquica adquiere nuevas posibilidades de respuesta y nivel de complejidad, es decir, alcanza un grado mayor de libertad e iniciativa.

Pero el crecimiento en el contexto terapéutico requiere ser refrendado en los distintos grupos de pertenencia; el "nuestro", aunque en ocasiones se contemple como refugio, tiene una vida limitada, cumple una función concreta en absoluto alternativa a las relaciones con el exterior. Los vínculos que se crean en el grupo son armazón sobre el que el proceso se dinamiza en espirales que convergen y discrepan, muy lejos de la linealidad, de la inmediatez, de lo racional... lo allí acontecido se confronta con lo inconsciente (por ejemplo en sueños), con el grupo actual, etc. Romper lo neuróticamente iterativo desde la perspectiva vincular conduce a un nuevo compromiso de investimentos narcisistas y objetales en el afuera.

La problemática que se incorpora desde cada estructura o núcleo básico de personalidad busca reconducir quizá una versión denostada de sí mismo que condenó al sometimiento, tal vez la insuflación narcisista del esquizoide sancionada con soledad, o bien el desconcierto al que conducen los contrastes enaltecidos del confuso. En esta línea, aplicando el modelo de Nicolás Caparrós (2004) a la descripción de la dinámica grupal, diríamos que se suceden escenas esquizoides (predomina lo propositivo o el repliegue narcisista), confusas (acción provocadora o bloqueo) o depresivas (espacio prínceps de elaboración si no se cae en manos de lo racional). Se necesita el concurso de las tres una y otra vez, en una espiral que alcanza espacios cada vez más íntimos, objetos individualizados en un mar de ansiedades compartidas, para retornar a la superficie donde los objetos son comunes, reales, pero portadores de muy diversos significados para cada sujeto.

Retomando a Kaës (inédito para Caparrós, 2010), recordemos que los grupos internos son los principales organizadores inconscientes del proceso de emparejamiento de los psiquismos y de la realidad psíquica inconsciente del grupo: "Son configuraciones inconscientes atravesadas por conflictos y su organización les permite recibir y repartir cargas pulsionales... hacen posible, mantienen y organizan el desarrollo de la realidad psíquica del grupo, los vínculos intersubjetivos y del proceso asociativo, según lógicas propias de lo Inconsciente".

Siendo así, acordaremos que el paisaje en el que se alimente esa organización inconsciente, reforzará unas cualidades en detrimento de otras. Por tanto, si en cada cultura, reflexión y actividad se nutren mutuamente transformando el quehacer en pensamiento, los factores de cambio variarán al ritmo de los mecanismos de defensa, en función del contexto, la patología de un sujeto, de los valores que impregnen su cultura... Tener que comunicar una experiencia implica el esfuerzo de poner palabras, de nombrar, cosa que ya en sí contraría al síntoma neurótico. La racionalización permite experiencias pulsionales en la medida que un sujeto consigue justificarlas y enmascararlas; las pulsiones ignoran normas, son, exigen satisfacción inmediata, pero topan con una realidad que pretende someterlas; la convivencia demanda su control. La represión actúa sobre la representación de la pulsión. La sublimación es otra propuesta que, además, contribuye a cimentar la base de una cultura en la medida en que cumple con las exigencias sociales, ofreciendo objetivos que no son inmediatos y se valoran socialmente.

Alternativas a la satisfacción directa de las pulsiones fueron ya descritas por Freud (1915/1968) que veía determinado su destino por la articulación entre lo corporal, lo psíquico y lo social. En el conflicto, que es inseparable de la condición neurótica, entran en litigio pulsiones que alternan en los escenarios regidos por los principios del placer y de realidad. El déficit que en el psicótico sustituye al conflicto y el juego pulsional se desempeña con mayor libertad en detrimento del principio de realidad. 
Represión, racionalización, sublimación, inhibición en cuanto al fin, todas ellas presentes en cualquier forma cultural, difieren en la intensidad de su injerencia y en la índole de la pulsión sobre la que actúan. Aquietar y desviar afectos y, como trasunto final, la palabra. Palabra como vehículo que condensa primero, traduce y elabora después, emociones fundamentales veladas por nuestra cultura. Palabra a desbaratar mediante el análisis, destinada a ser más tarde recompuesta con la interpretación a través de la que adquiere cualidad de "factor de curación". Discurso deconstruido como prólogo a una nueva construcción.

\section{Y el proceso continúa...}

Al iniciarse un grupo cada cual se aferra a una versión de sí y de su propia historia, ignorando la cantidad de pormenores que inconscientemente aporta y a través de los que los demás dibujarán otro perfil del que se pretendió mostrar. Este hecho -urdido con proyecciones e introyecciones- que en principio podría incomodar, es una de las vías privilegiadas para desestabilizar la rigidez neurótica. La dinámica se pone en marcha en un marco de seguridad: el respaldo de una institución, el encuadre, la alianza terapéutica... en suma, lo depositado transferencialmente en lo que conforma la estructura del dispositivo terapéutico; esto genera un espacio de contención en el que las defensas se relajan y donde aflora lo hasta entonces retenido, con un monto de ansiedad tolerable.

La colisión entre las exigencias de las realidades interna y externa dinamiza el proceso de estructuración. Esta apremiante bipolaridad y alternativas para avanzar a su través, se multiplican en el encuentro de grupalidades internas que supone el espacio de análisis que presentamos. Lo pulsional se activa, sujetos reales acogerán y distorsionarán a los imaginarios y el narcisismo habrá de modularse. En el grupo psicoanalítico los procesos de reestructuración abren espacio a una multiplicidad de identificaciones que reubican el grupo primario a través del que se constituyó un sujeto. Reconocer en la emoción que despierta un compañero la sombra de un objeto interno rompe enigmas. El ir y venir entre las emociones actuales en lo horizontal y a lo intrapsíquico -actual y remoto-, provoca desestructuraciones puntuales que posibilitan la emergencia de nuevas estructuras simbólicas.

Si el vínculo es diferencia y nace de ésta, el grupo da forma y coherencia a los movimientos pulsionales que el existir en sociedad genera. Tras el momento del precavido reconocimiento esquizoide, la renegación propia de la situación confusa permite el desorganizado fluir de material inconsciente en el grupo terapéutico... Nuevos vínculos entre sujetos desconocidos se originan en un microcosmos concreto; la ambivalencia, resorte de la acción en el grupo, proviene del pensar reflexivo que entraña renuncia a capacidades más básicas. Cuando una función como la agresión se convierte en fuente de placer a través del juego, ayuda a crear espacio propio, a soportar la frustración, a deambular por las contradicciones y aceptar la ambivalencia.

La identidad de un sujeto no se perfila con la línea corporal que lo delimita; lo que se cuenta a sí mismo de su propia historia, la sombra que percibe de su representación de objetos internalizados, la disposición para expresarse con modulaciones que difieren en función del lugar, del momento, del tipo de vínculo en el que esté inmerso en cada momento... la experiencia, el "ser" no puede reducirse a la categoría de una verdad objetiva. Verdad y Realidad se escabullen y engañan haciendo desfilar fugaces representaciones de lo que se fue y de lo que se intuye se es, en una inabordable tarea de atisbar la entraña de lo inconsciente. En cualquier caso, el grupo se presta como escenario en el que avanzar algo en este juego del escondite...

Exclamemos con Bugs Bunny: “iQQué hay de nuevo, viejo!!”.

\section{Referencias}

Caparrós, N. (2004). Grupo: organización, estructura y proceso. En N. Caparrós, I. Sanfeliu, A. Ezquerro, R. Kaës, C. Neri, y E. Rodrigué, ...Y el grupo creó al hombre (pp. 23-100). Madrid: Biblioteca Nueva. Caparrós, N. (2011). Viaje a la complejidad. Madrid: Biblioteca Nueva. 
Freud, S. (1968). Las pulsiones y sus destinos. En Obras Completas. Madrid: Editorial Biblioteca Nueva. (Original publicado en alemán en 1915).

Napolitani, D. (1998). Más allá de las convicciones individualistas. Clínica y análisis grupal, 47, 7-17.

Sanfeliu, I. (1998). Yo en los otros, los otros en mí: grupo y procesos identificativos. En N. Caparrós (Ed.), Del narcisismo a la subjetividad: el vínculo (pp.125-150). Madrid: Biblioteca Nueva.

Sanfeliu, I. (2007). Espacio imaginario en un grupo de psicóticos. Clínica y análisis grupal, 98, 103-117.

Sanfeliu, I., Díaz Sanfeliu, L., Fernández Belinchón, C., Moreno, A., Román, T. y Santos, B. (2009). De la ternura y sus acentos. Clínica y análisis grupal, 103, 111-134.

\section{Vínculos de interés}

Imago Clínica Psicoanalítica: www.imagoclinica.com

Manuscrito recibido: $13 / 12 / 2010$

Revisión recibida: 28/01/2011

Manuscrito aceptado: 31/01/2011 